
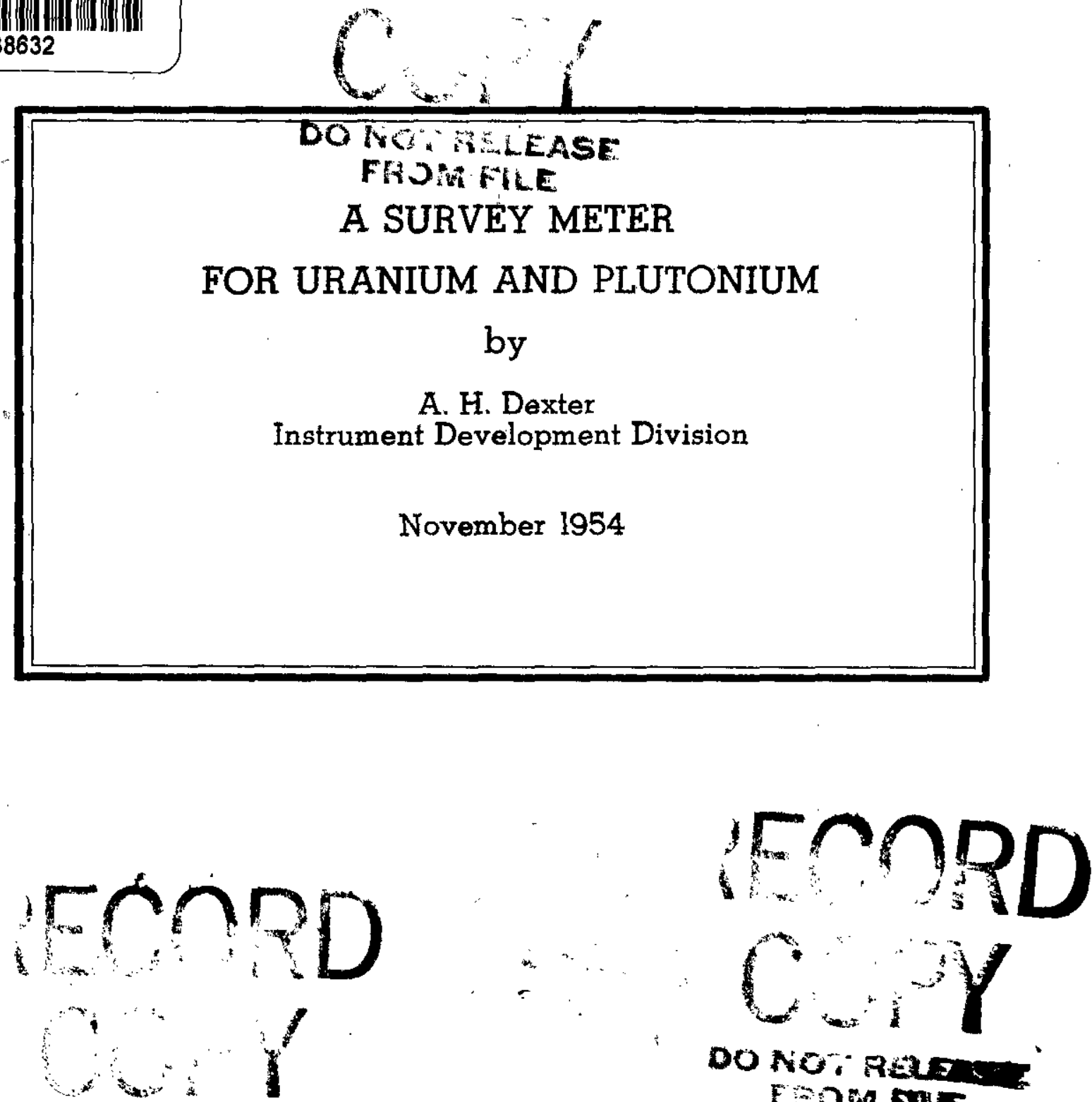

OSAOM

TRO IR Fits E.I. du Pont de Nemours \& Co.

Explosives Department - Atomic Energy Division

Technical Division - Savannah River Laboratory 


\section{A SURVEY METER FOR URANIUM AND PLUTONIUM}

by

A. H. Dexter

Instrument Development Division

November 1954

E. I. du Pont de Nemours \& Co.

Explosives Department - Atomic Energy Division Technical Division - Savannah River Laboratory

Printed For

The United States Atomic Energy Commission

Contract AT $(07-2)-1$ 
Copy No.

$$
\begin{array}{rlr}
\text { 1-5. AEC, SROo } & \text { Augusta, Ga. } \\
\text { 6. R. M. Evans - } & \\
\text { B. H. Mackey } & \text { Wilmington AED } \\
\text { 7. W. C. Kay - M. H. Smith } & " \\
\text { 8. J. B. Tinker } & \\
\text { 9. L. Squires- } & \text { H. Worthington } & " \\
\text { 10. D. F. Babcock } & " \\
\text { 11. "W" File } &
\end{array}
$$

12. J. A. Burns

13. W. P. Overbeck

14. J. D. Ellett

15. T. C. Evans

16. H. J. Bowman

17. J. D. Cist

18-19. C. M. Patterson

20. PRD File

21. M. H. Wahl -

C. W. J. Wende

22. J. W. Croach -

I. M. Arnett

23. J. N. Wilson

24. D. E. Waters

25. A. J. Hill -

G. M. Nichols

26. R. N. Tetzlaff

27. A. H. Dexter

28-42. TIS File

43. TIS File Record Copy
Engineering Department

Savannah River Plant

Savannah R1ver Laboratory 
$D P-62$

Page 3

INSTRUMENTATION EXTERNAL DISTRIBUTION

(TID-4500, 8th Ed.)

Copy No.

44. Argonne Cancer Research Hospital

45-48. Argonne National Laboratory

49-53. Armed Services Technical Information Agency, Dayton

54-55. Army Chemical Center

56. Army Medical Research Laboratory

57. Army Medical Service Graduate School

58. Atomic Energy Commission, Patent Branch

59-61. Atomic Energy Commission, Technical Iubrary

62. Atomic Energy of Canada Limited

63. Australian Atomic Energy Commission

64. Battelle Memorial Institute

65. Belgium, Centre d'Etudes pour les Applications de l'Energie Nucleaire

66-68. Belgium, Union Miniere du Haut Katanga

69-72. Brookhaven National Laboratory

73. Bureau of Ships (Code 490)

74-75. Canadian Joint Staff (Taber)

76. Carbide and Carbon Chemicals Company, C-31 Plant

77-78. Carbide and Carbon Chemicals Company, K-25 Plant

79-84. Carbide and Carbon Chemicals Company, ORNL

85-86. Carnegie Institute of Technology

87-90. Chalk River Project, Canada

91. Chicago Patent Group

92. Columbia University (Dr. Failla)

93-94. Columbia University (Dr. Hassialis)

95. Commonwealth X-Ray \& Radium Laboratory

96-97. Consolidated Vultee Aircraft Corporation

98. Department of Army, Office of Ordnance Research

99. Department of Navy, Code 811

100-101. Division of Raw Materials, Denver

102. Division of Raw Materials, Ishpeming

103. Division of Raw Materials, Salt Lake City

104-105. Dow Chemical Company, Midland

106. Dow Chemical Company, Rocky Flats

107-108. Eldorado Mining and Refining Limited

109. Frankford Arsenal

110-111. General Electric Company (ANPP)

112-114. General Electric Company, Richland

115-117. Goodyear Atomic Corporation

118. Harshaw Chemical Corporation

119-120. Iowa State College

121. Italy, Centro Italian Studi Experienze

122. Kaiser Engineers

123. Kirtland Air Force Base

124-125. Knolis Atomic Power Laboratory

126-127. Los Alamos Scientific Laboratory

128. Mallinckrodt Chemical Works 


\section{EXTERNAL DISTRIBUTION (Continued)}

Copy No.

129. Massachusetts Institute of Technology (Dr. Kaufmann)

130. Mound Laboratory

131. National Advisory Committee for Aeronautics, Cleveland

132. National Bureau of Standards, Atomic Energy Project

133. National Bureau of Standards, Library

134. National Lead Company of Ohio

135. National Research Corporation

136-138. National Research Council, Canada

139. Naval Medical Research Institute

140-142. Naval Research Laboratory

143. New Brunswick Laboratory

144. Newport News Shipbuilding and Dry Dock Company

145. New York Operations Office

146. North American Aviation, Inc.

147. Nuclear Development Associates, Inc.

148. Oak Ridge Institute of Nuclear Studies

149-152. Phillips Petroleum Company

153. Princeton University

154-156. Public Health Service

157. RAND Corporation

158. Sandia Corporation

159-243. Technical Information Service, Oak Ridge

244. The Surgeon General

245. Tokyo University

246. United Aircraft Corporation

247-261. United Kingdom Scientific Mission

262-263. U.S. Geological Survey (Mr. Butler)

264-265. U.S. Naval Radiological Defense Laboratory

266. UCLA Medical Research Laboratory

267-268. University of California Radiation Laboratory

269-271. University of California Radiation Laboratory, Livermore Site

272. University of Chicago, A. F. Radiation Laboratory

273-274. University of Michigan (Dr. Gomberg)

275-276. University of Rochester, Atomic Energy Project

27\%. University of Utah

278. University of Washington, Applied Fisheries Laboratory

279. Vitro Corporation of America

280. Walter Kidde Nuclear Laboratories, Inc.

281. Watertown Arsenal

282-285. Westinghouse Electric Corporation

286. Yale University (Dr. Wadey) 
$D P-62$

Page 5

\begin{abstract}
$\underline{\text { ABSTRACT }}$
A portable instrument is described that can distinguish between plutonium and uranium contaminants by detecting the difference in range of their respective alpha particles in air.
\end{abstract}


INTRODUCTION . . . . . . . . . . . . . 7

SUMMARY . . . . . . . . . . . . . . 7

DISCUSSION . . . . . . . . . . . . 8

The Spark Counter............... 8

The Uranium - Plutonium Survey Meter ...... 9

Operation . . . . . . . . . . . . . 10

Sensitivity ................. . 11

Performance ................. . II

BIBLIOGRAPHY ................ . . 12

\section{LIST OF FIGURES}

Figure 1. Research Model of the Spark Counter ... 13

Figure 2. Spark Counter Circuit ........ 14

Figure 3. Count Rate vs. Voltage, Unevenly

Spaced Wires ........ 15

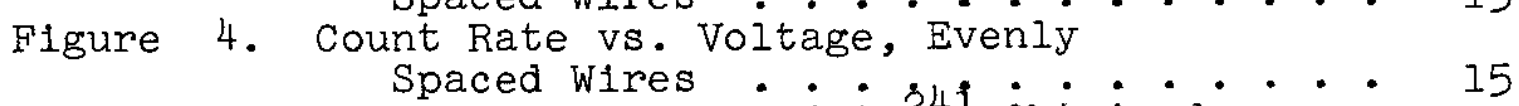

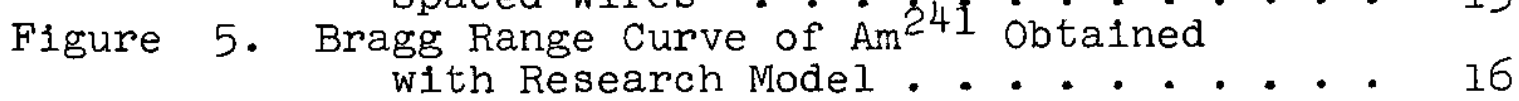

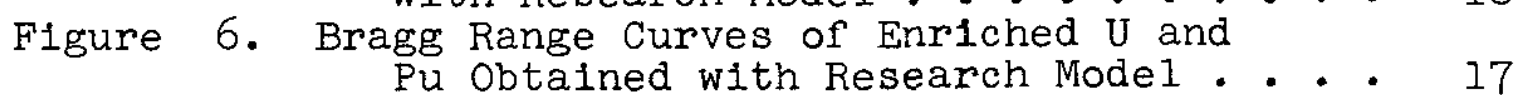

Figure 7. Survey Meter and High Voltage Supply... 18

Figure 8. Interior View of Survey Meter ...... 19

Figure 9. Survey Meter, Bottom View ....... 20

Figure 10. Circuit Diagram of Survey Meter .... . 21

Figure 11. Bragg Range Curves of Enriched U and

Pu Obtained with the Survey Meter . • 22

Figure 12. Bragg Range Curves of Natural U and
Pu Obtained with the Survey Meter... 23 


\section{INTRODUCTION}

When alpha radioactive contamination is found in installations handling both uranium and plutonium, it is often desirable to determine which element is the contaminant, since there is a greater physiological hazard associated with plutonium. If a smear with sufficient activity can be obtained, the contaminant can usually be identified with a special alpha-particle analyzer. However, a direct and rapid determination of the contaminant at the source is much preferred. No portable survey instrument was known which was capable of making such a determination.

This report describes the development and construction of an instrument to fill the need for an improved survey meter.

\section{SUMMARY}

A survey meter was developed to distinguish plutonium contamination from uranium. The instrument consists of an alpha counter with a very "shallow" sensitive depth and a means for accurately positioning the alpha counter relative to the source of contamination. Since the alpha particles emitted by plutonium have a greater range in air (by $0.78 \mathrm{~cm}$ ) than those emitted by uranium, the instrument can 1dentify the contaminant by measuring the range of alpha particles which are emitted. The survey meter is a selfcontained portable instrument which operates on 110 volts A.C. 
$D P-62$

Page 8

DISCUSSION

The instrument distinguishes between plutonium and uranium on the basis of the difference in range of the alpha particles emitted by the substances.

The most energetic alpha-emitting 1sotope of uranium is $\mathrm{U}^{234}$ which emits alpha particles with an energy of $4.76 \mathrm{Mev}(1)$. About $49 \%$ of the alpha particles emitted by natural uranium and almost all of the alpha particles emitted by enriched uranium are due to $\mathrm{y}^{234}$. The most energetic plutonfum alpha emitter is $\mathrm{Pu}^{238}$ which emits alphas of 5.49 Mev (2) (3). Since the $\mathrm{Pu}^{23} 8$ content of plutonium is a function of the exposure of uranium in a pile, it is not possible to set a definite value for the percentage of alpha emissions due to $\mathrm{Pu}^{238}$ in plutonium.

The range (4) in air of the $4.76 \mathrm{Mev}$ alpha particle is $3.24 \mathrm{~cm}$, and that of the $5.49 \mathrm{Mev}$ alpha particle is 4.02 $\mathrm{cm}$.

Any alpha activity registered by an appropriate counter, placed at a distance slightly greater than $3.24 \mathrm{~cm}$ but less than $4.02 \mathrm{~cm}$ from a known source of contamination, identifies the contaminant as plutonium. Conversely, the absence of any detectable alpha activity at this distance indicates uranium.

The two most promising alpha counters for this application were the scintillation counter and the spark counter. The former was rejected because the necessary light-tight window would confuse the difference in the alpha track lengths. Ag investigation was therefore made of the spark counter $(5-8)$.

THE SPARIK COUNTER

In its simplest form, the spark counter consists of a tungsten wire, approximately 0.003 inch in diameter, stretched parallel to and about $1 \mathrm{~mm}$ distant from an aluminum plate. When a potential of 3,000 to 5,000 volts is impressed between the wire and plate, a visible corona appears around the wire. If an alpha particle passes near the wire, it ionizes the air and a spark discharge occurs. The sparks are both visible and audible. Since the sensitive region of the counter is closely limited to the small region of corona surrounding the wire, the spark counter has a very "shallow depth", a requisite for the measurement of small differences in range of alphas. The counter is windowless and operates in air.

A simple, four-wire, "guitar-type" counter was constructed. The instrument is shown in Figure 1 and the circultry in Figure 2. 
The variation of count rate with applied, voltage was determined with the counter placed over an $\mathrm{Am}^{241}$ source; the alphas were normally incident to the plate of the spark counter. The curve obtained (Figure 3) was extremely irregular, probably because the wires were not properly parallel to the plate. The counter was subsequently restrung with more care and a fifth wire was added. The curve obtained (Figure 4) shows a reasonable plateau, approximately 200 volts in length (4400 - 4600 volts) with a slope of about $0.02 \%$ change in counts per volt. These results are in excellent agreement with those of $R$. D. Connor (7), who obtained 250-volt plateaus with a slope of $0.06 \%$ change in count perpyolt, but in disagreement with those of $G$. G. Eichholz $(8)$ who did not obtain a plateau for normal incidence of the alpha particle.

The $\mathrm{Am}^{241}$ source was next mounted on the end of a screw so that the variation of count rate could be obtained as the source was moved away from the counter (see Figure 5).

Range curves of alpha particles from enriched uranium and plutonium were taken in a similar manner (Figure 6). The apparent range of alphas from plutonium is approximately $0.64 \mathrm{~cm}$ greater than for enriched uranium. This is true whether one uses the extrapolated range or the end point range. The experimental difference in range is within $20 \%$ of the predicted difference in range. These measurements established the principle of utilizing the range of the alpha particles to distinguish plutonium from uranium.

The spark counter has a background of 1 count per hour and is insensitive to beta and gamma radiation.

THE URANIUM - PLUTONIUM SURVEY METER

The prototype survey meter and associated highvoltage supply are shown in Figure 7. The instrument is portable, but operates on 110 volts A.C. The survey meter consists of a spark counter that is enclosed in an aluminum housing. The wire-to-plate spacing is about $1 \mathrm{~mm}$. The spark counter is mounted on a lucite block which can be raised or lowered by means of a screw with 20 threads/inch. The knob that turns the screw is a 15 turn "Duodial" located on the top of the survey meter. These features may be seen in Figure 8 which is a view of the meter with one of the side covers removed. Some of the associated capacitors and resistors of the survey meter circuit can also be seen in this view.

The alpha particles enter through a screened opening in the bottom of the instrument (Figure 9). The screen is positioned above the bottom surface of the instrument to avoid contamination of the screen. 
The spark counter is entirely enclosed and inaccessible to the operator; thus, there is no possibility of his coming in contact with the high voltage.

The two electrical connectors on the end of the survey meter are used for the high voltage input and signal output. The latter is provided in the event that it is desired to connect the survey meter to a scaler in order to obtain a range curve. The spark counter and high voltage circuits are shown in Figure 10. Note that the high voltage output is negative. Satisfactory operation is obtained only with a negative high voltage. The operating voltage is approximately 4500 volts. An exterior "stop" on the rheostat of the high voltage supply assures correct setting of the voltage.

\section{OPERATION}

To start the instrument, turn the HIGH VOLTAGE control on top of the high voltage supply fully clockwise, plug the high voltage supply into a convenient 110 volt - 60 cycle outlet, and throw the POWER switch to "ON". After a minute or two of warm up, turn the HIGH VOLTAGE control counterclockwise until it reaches the limiting stop.

To standardize the survey meter, place it over a uranium source and adjust the "Duodial" until no count is indicated by the indicator light on top of the survey meter. Next place it over a plutonium source to make certain that the spark counter has not been raised beyond the range of the plutonium alpha particles. Once this optimum setting has been obtained, the instrument is ready for survey work. Care should be taken that the top surfaces of the uranium and plutonium standards are flush with the bottom of the instrument when the standarization is made. Moreover, the standardization should be performed under conditions of room temperature and pressure that are appropriate to the site where the survey is to be made, since the range of the alpha particles is a function of alr temperature and pressure.

To examine unknown sources of contamination, place the survey meter on the surface to be examined and note the indicator light. If the light flashes at a rate significantly greater than the background of one count per hour, the presence of plutonium is indicated.

On occasion, it may be desirable to plot a Bragg range curve of the alpha particles from an unknown source of contamination for comparison with a known alpha source. This is accomplished by connecting the output of the survey meter to a scaler. The count per unit time as a function of "Duodial" setting is then plotted. Curves taken in this manner with the survey meter, for uranium and plutonium, are shown in Figures 11 and 12. 
An estimation of the sensitivity of the instrument is obtained by considering Figure 11. For the optimum "Duodial" setting of 17, the two elements (U and Pu) are easily differentiated, and the plutonium count rate is $70 \mathrm{c} / \mathrm{m}$. The Pu source was actually emitting 27,300 alphas/minute in the $2 \pi$ space above its surface. Accordingly, a source of 400 alphas/minute will give about $1 \mathrm{c} / \mathrm{m}$ at this range.

By way of comparison, one of the best available alpha survey instruments, the scintillation AC Poppy (9), has a threshold of detection of approximately 100 alphas/minute in the same $2 \pi$ space. It should be emphasized, however, that the uranium-plutonium survey meter was not developed for routine survey work. It is intended for the identification of contamination once it has been found in the course of routine survey work with a scintillation Ae Poppy or a similar instrument.

Measurements of sensitivity were made for standard survey instruments used at SRL to determine how long the uranium-plutonium survey meter should be left over the source of contamination for proper identification. These "rule of thumb" measurements indicate that if the meter reading (c/s) of the scintillation AC Poppy is divided into 10, the approximate number of minutes required is given. For example, if the $\mathrm{AC}$ Poppy reads $5 \mathrm{c} / \mathrm{s}$, the time required for the identification will be $10 / 5$ or 2 minutes.

For the Samson alpha-survey meter (10), the rule is: 1000 divided by the meter reading (counts/minute) gives the time required in minutes. For example, if the reading on the samson meter is $500 \mathrm{c} / \mathrm{m}$, the time required for the identification will be $1000 / 500$ or 2 minutes.

PERFORMANCE

The instrument accurately identified small evaporated sources of uranium and plutonium in the laboratory. Inexperienced personnel were able to standardize and use the instrument after only a few minutes instruction.

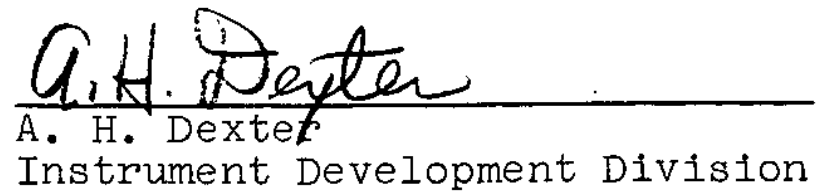




\section{BIBLIOGRAPHY}

1. GhIorso, A. Phys. Rev. 82, 979 (1951).

2. Asaro, F., and Perlman, I. Unpublished data (November 1952).

3. Asaro, F. UCRL-2180, 105 (June 1953).

4. Holloway, M., and Livingston, M. S. Phys. Rev. 5418 (1938).

5. Chang, W. Y., and Rosenblum, S. Phys. Rev. 67, 22 (1945).

6. Guimaraes, M. A., and Sampiro, P. A. Rev. Sc1. Instru. 19, 475 (1948).

7. Connor, R. D. J. Sc1. Instr. 29, 12 (1952).

8. Eichholz, G. G. Nucleonics 10, No. 10, 46 (1952).

9. "Scintiliation AC Poppy Probe". Cat. 123C273Gl, General Electric Co.

10. Samson Alpha. Survey Meter, Mode1 D-5, Radioactive Products,Inc., Detroit, Michigan. 


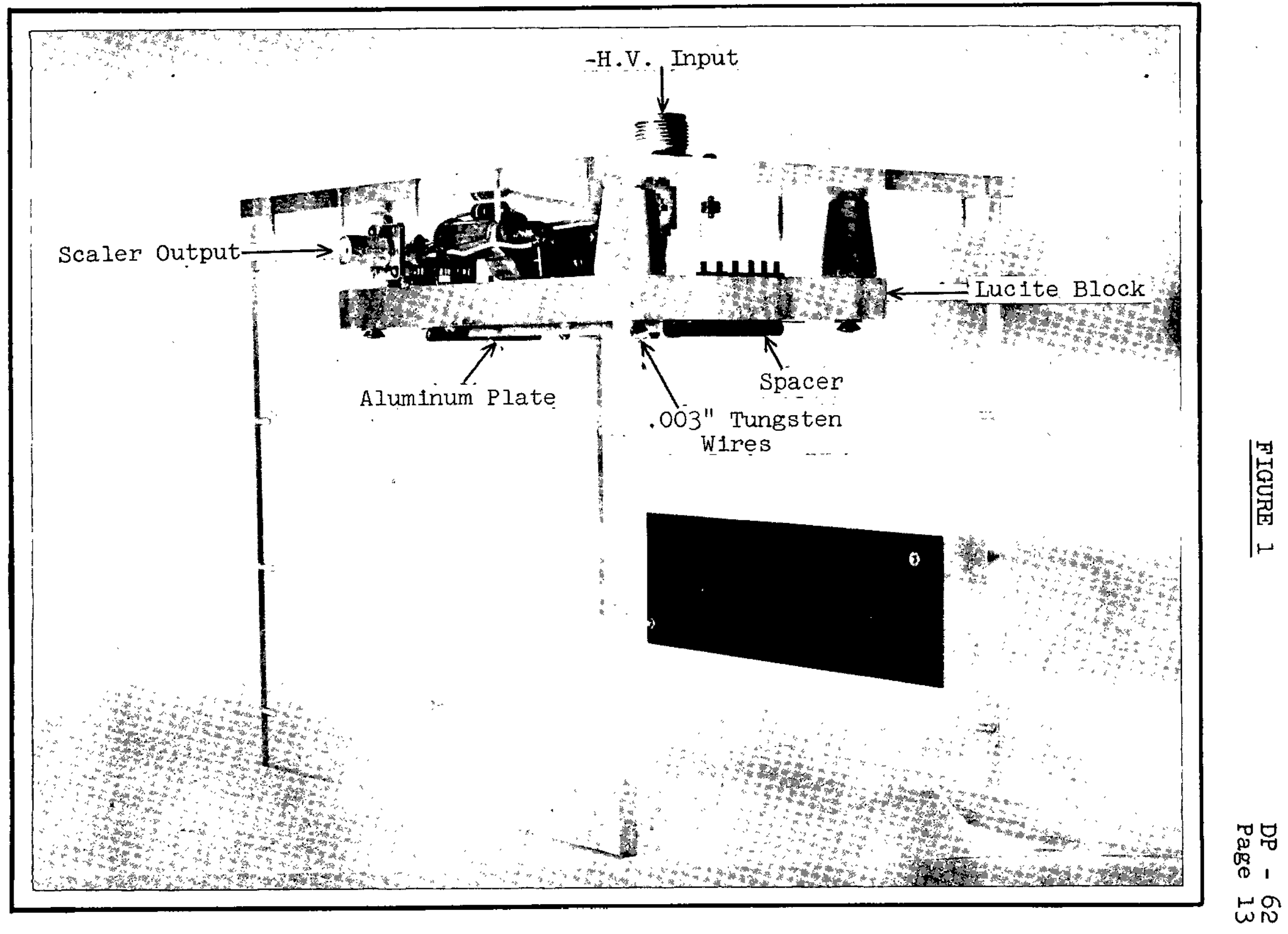

RESEARCH MODEL OF THE SPARK COUNTER 


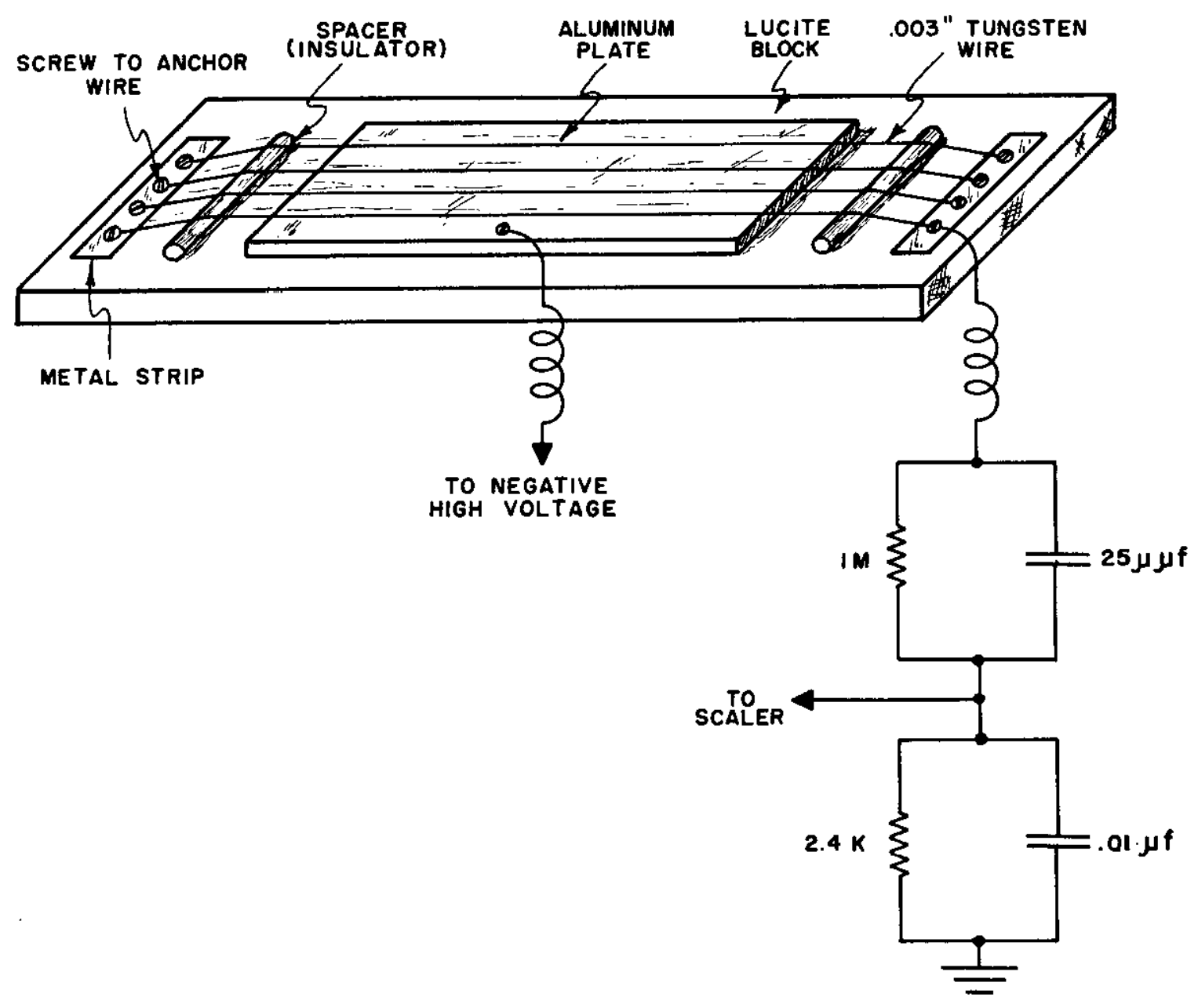




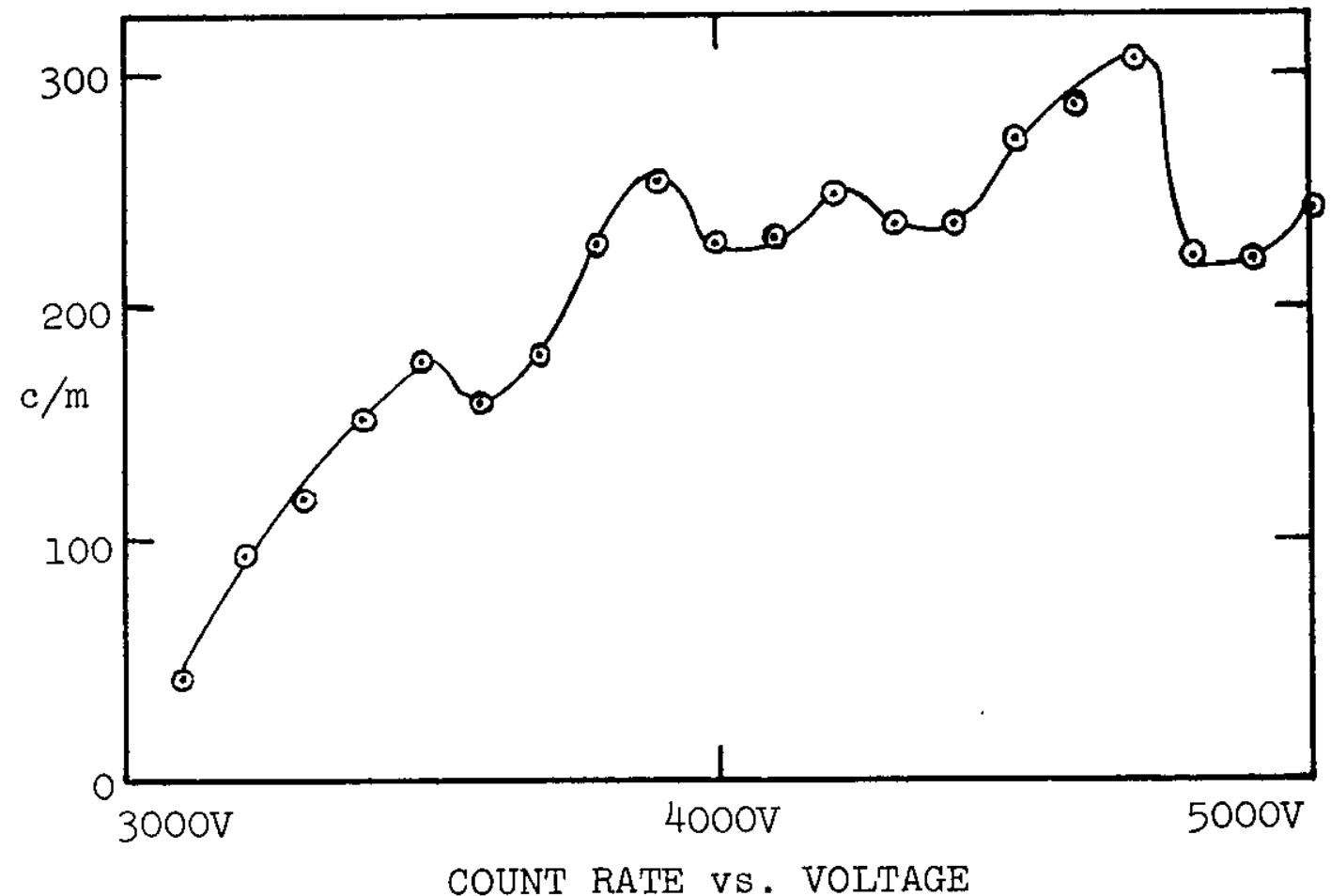

(Unevenly Spaced Wires)

FIGURE 4

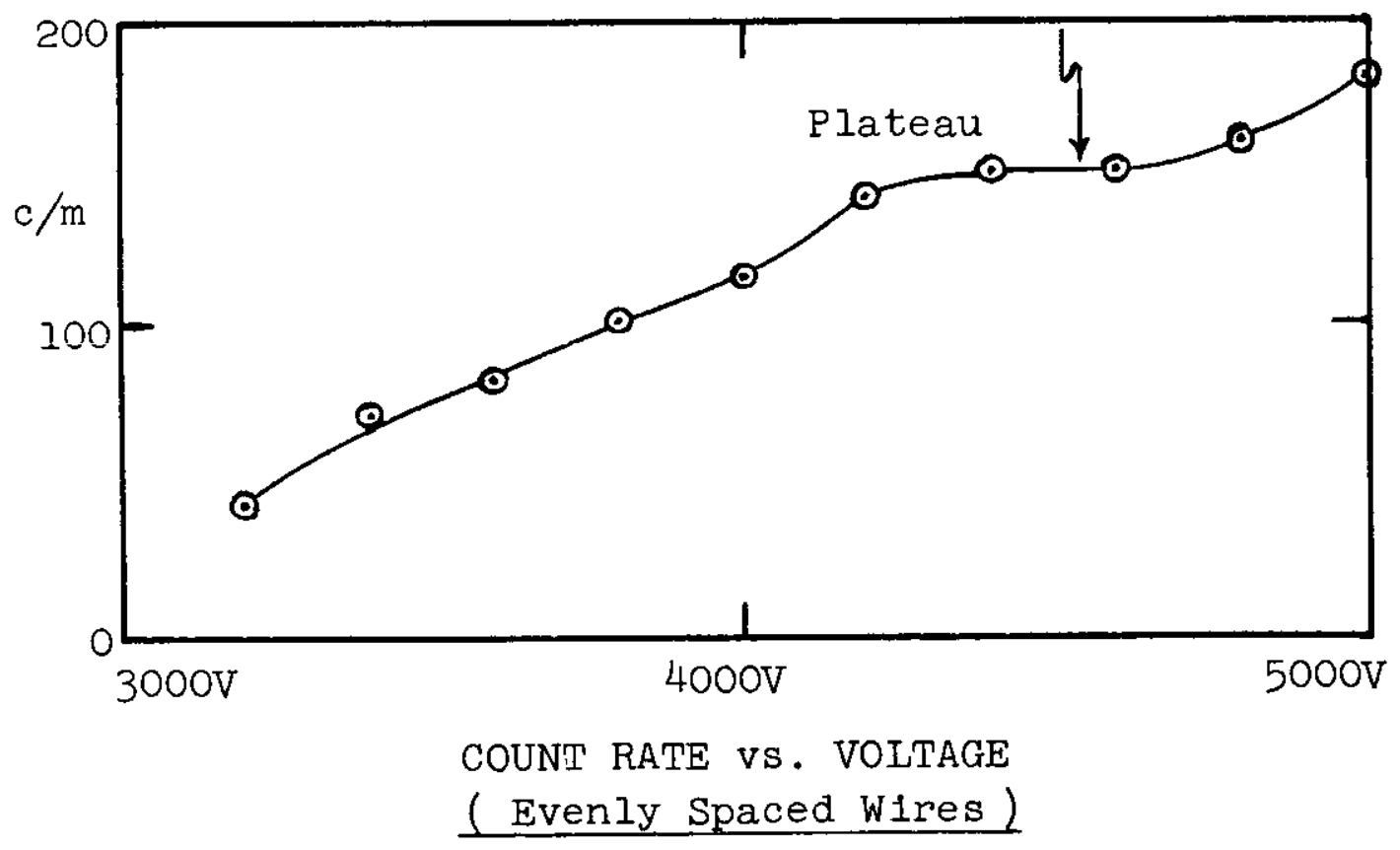




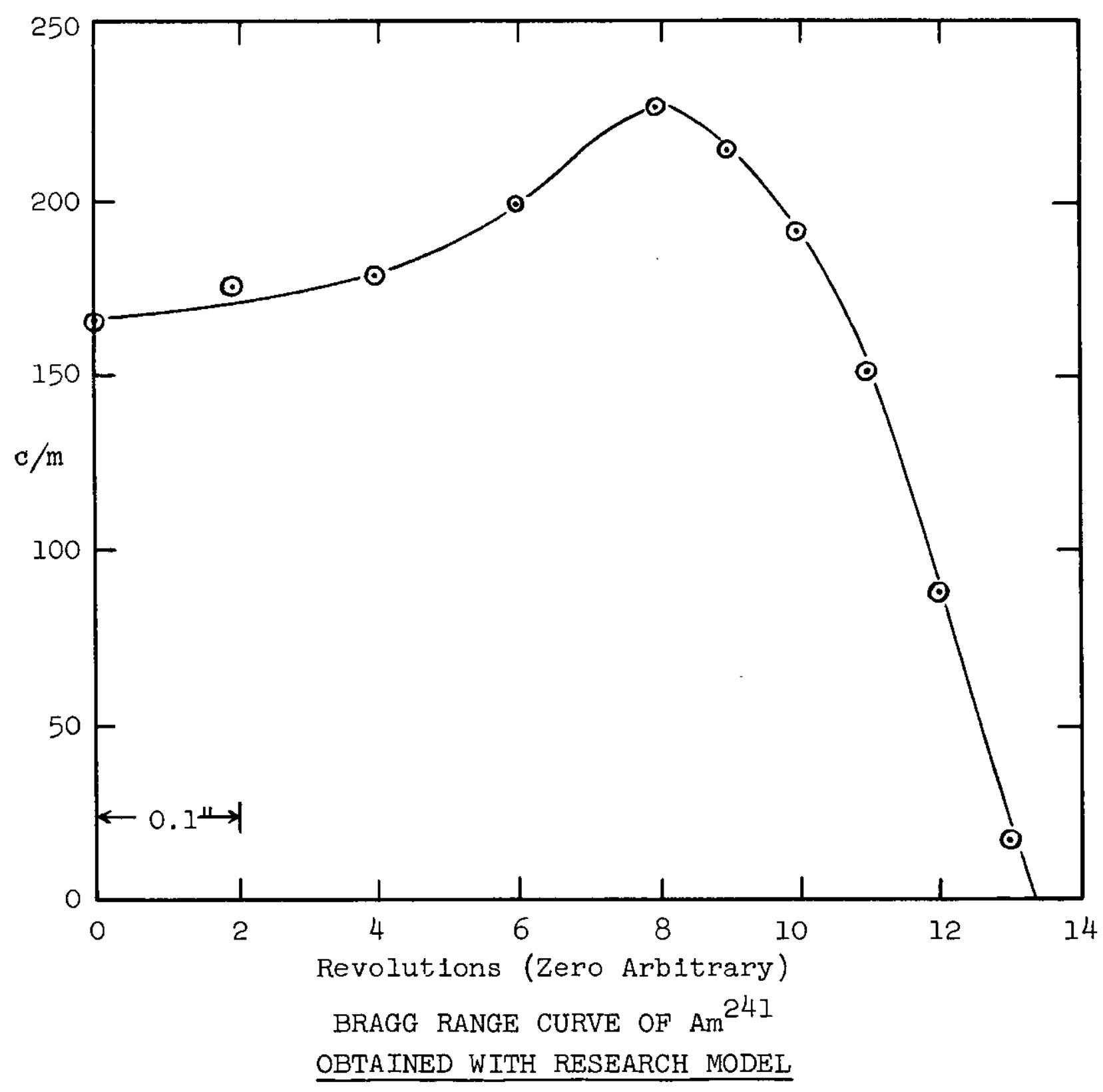




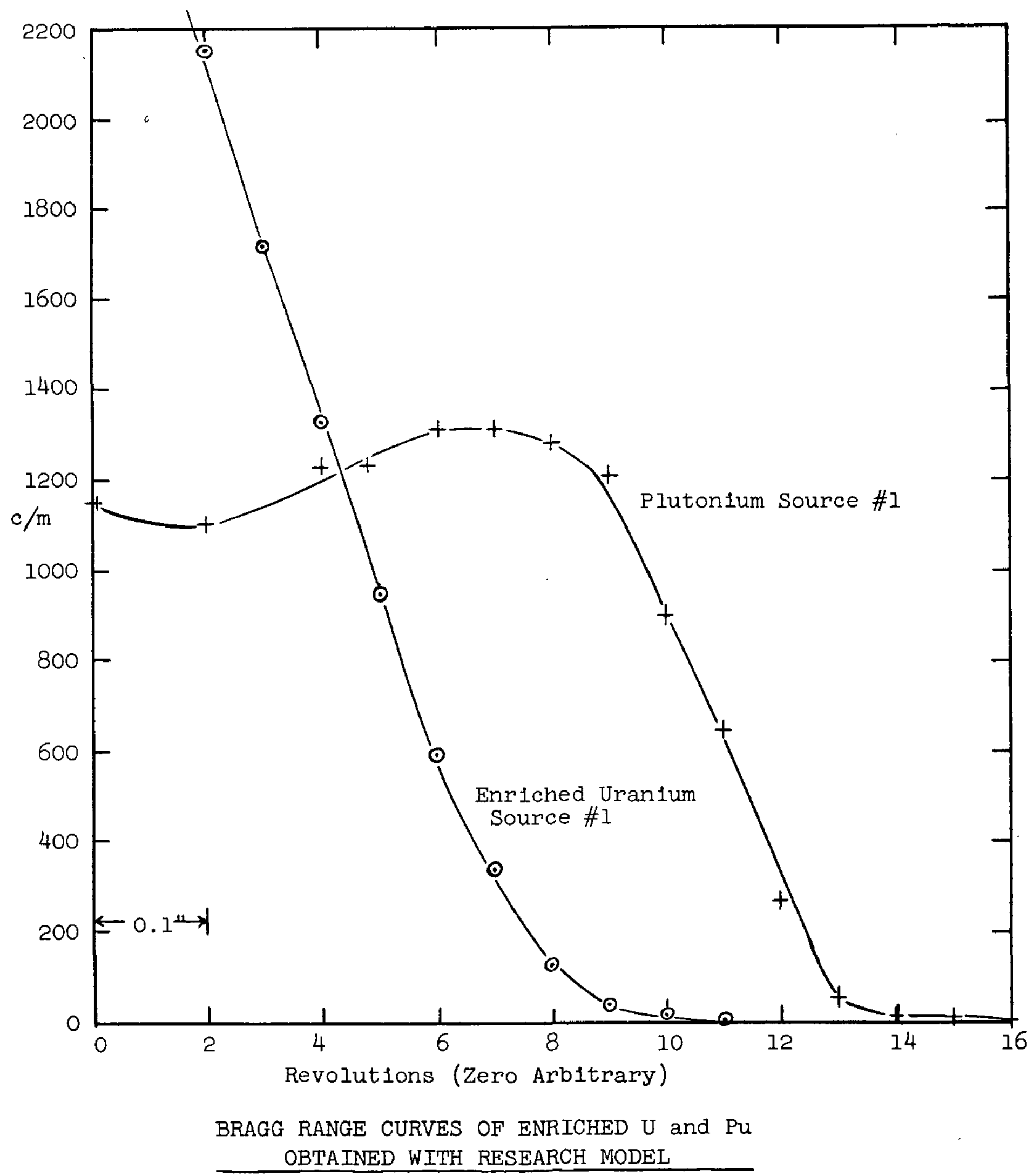




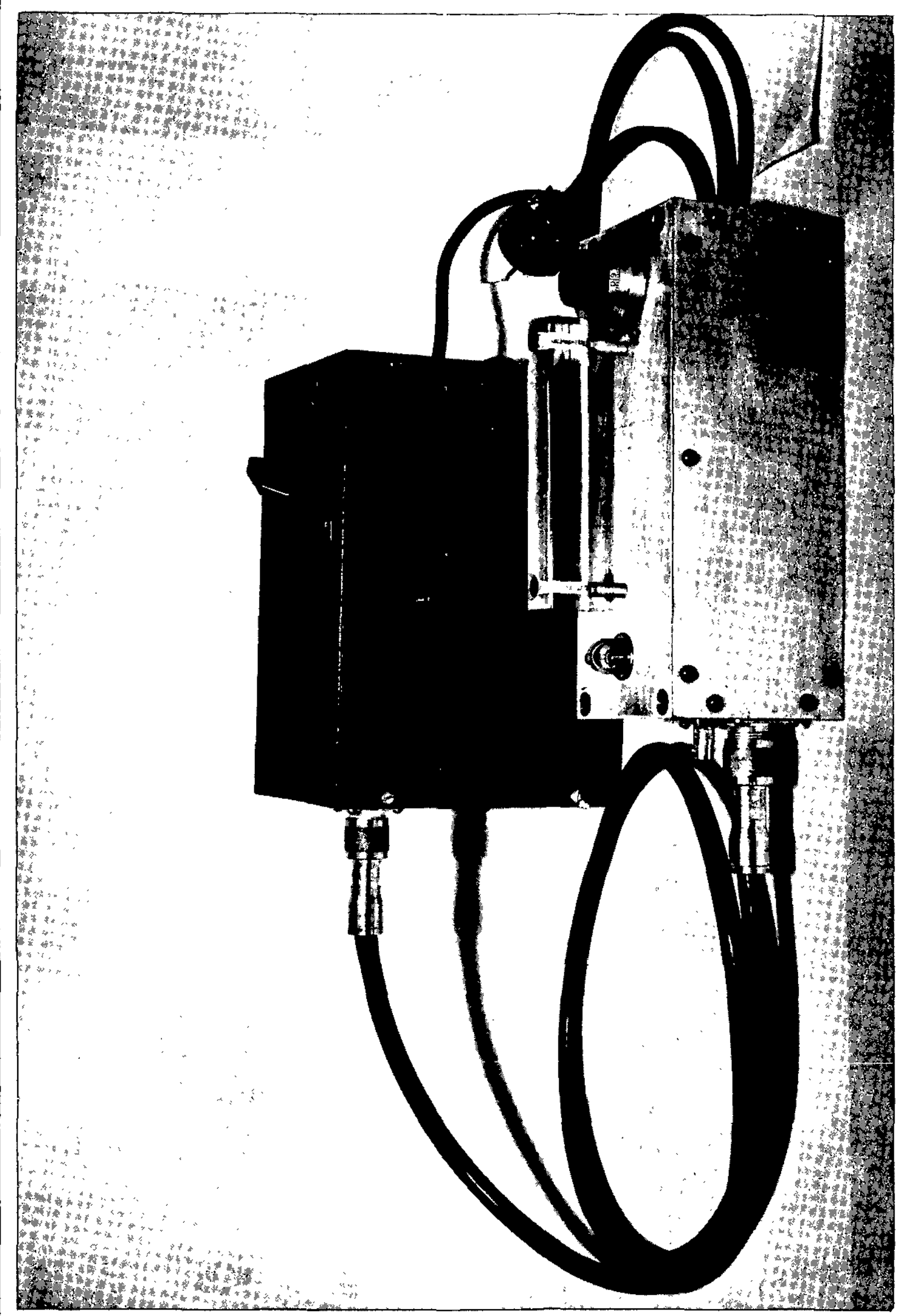

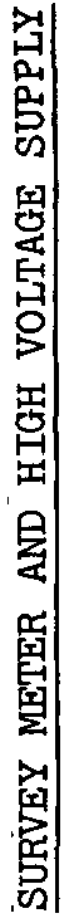




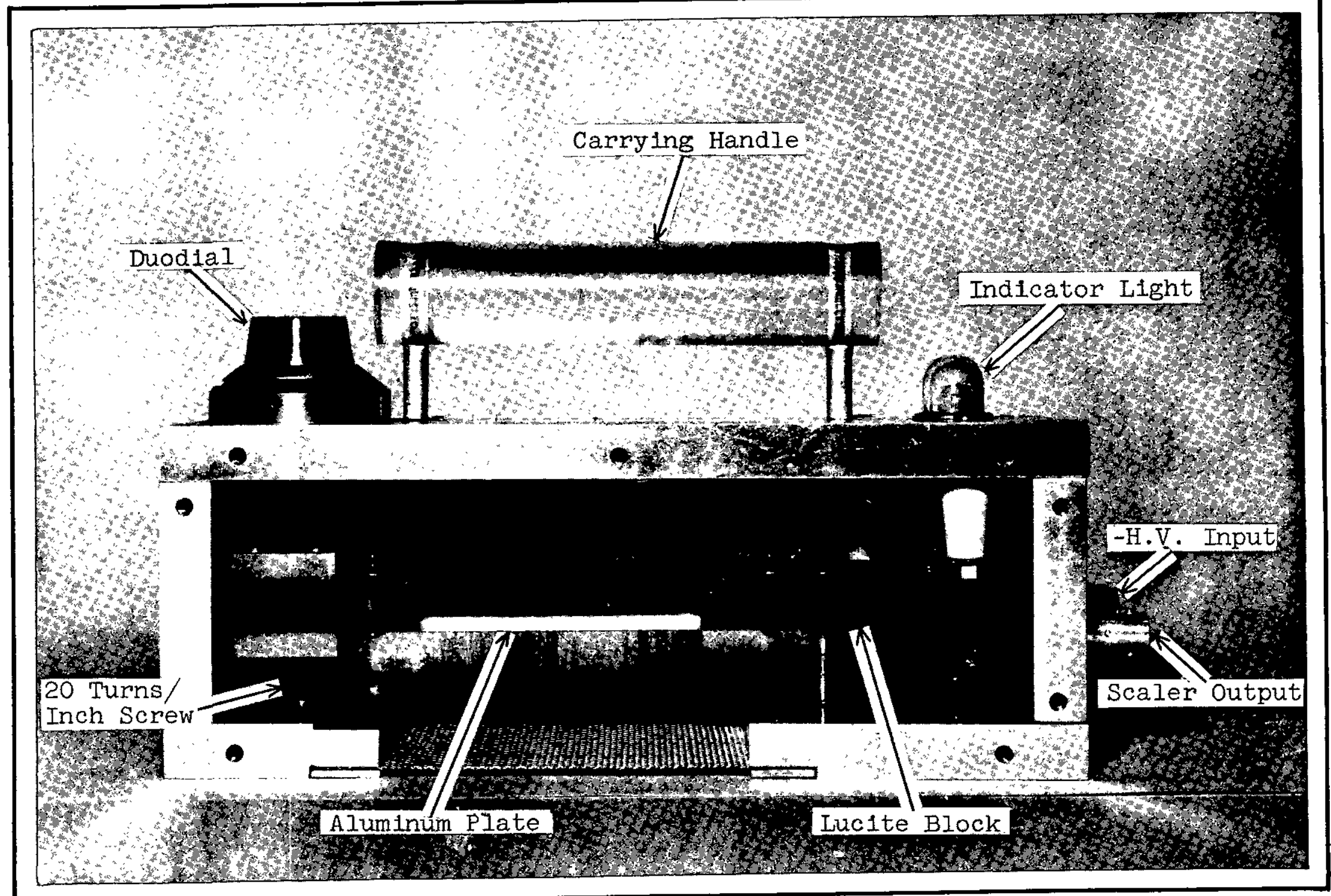

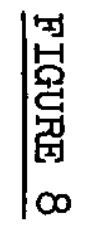




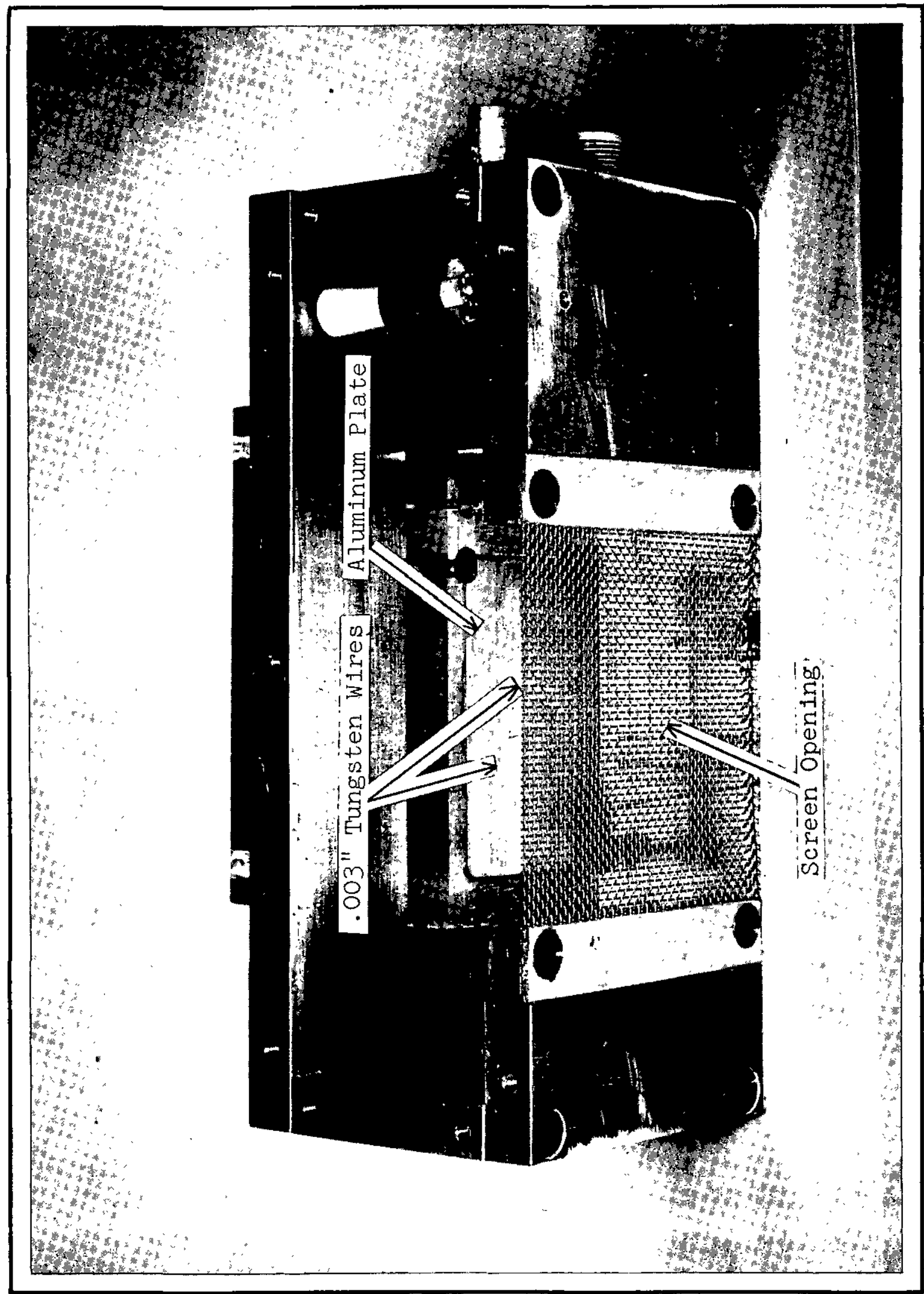

周 


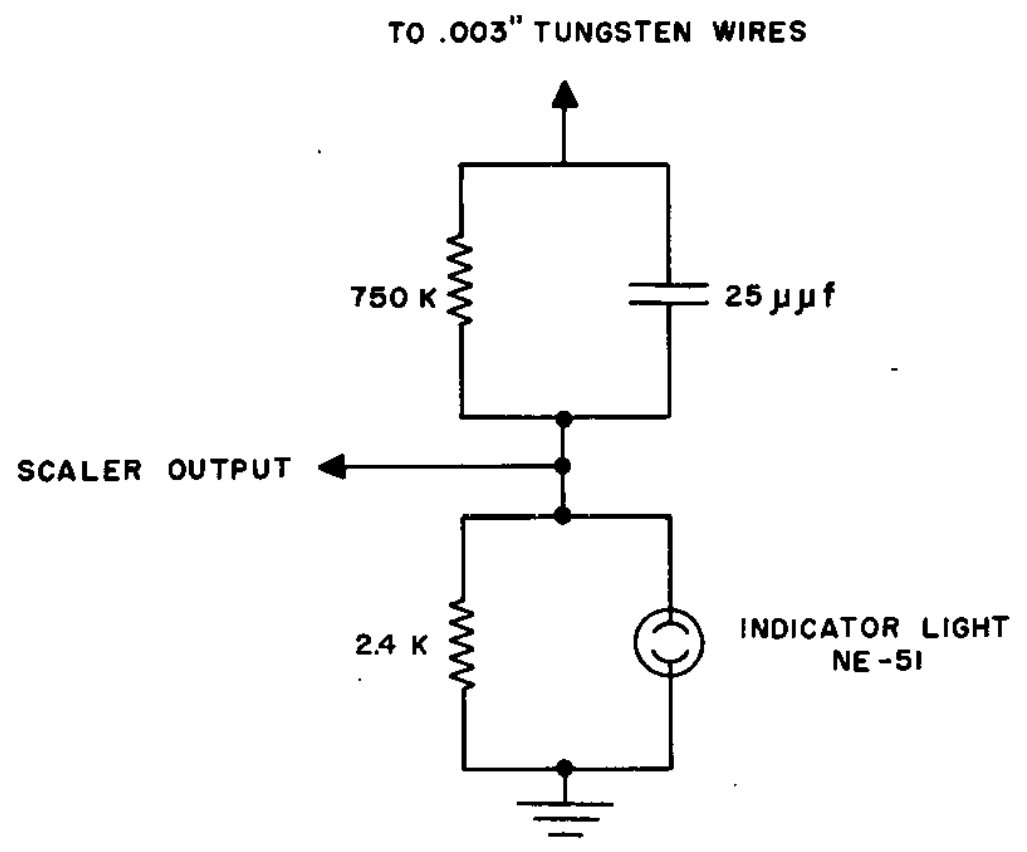

(a) SPARK COUNTER CIRCUIT

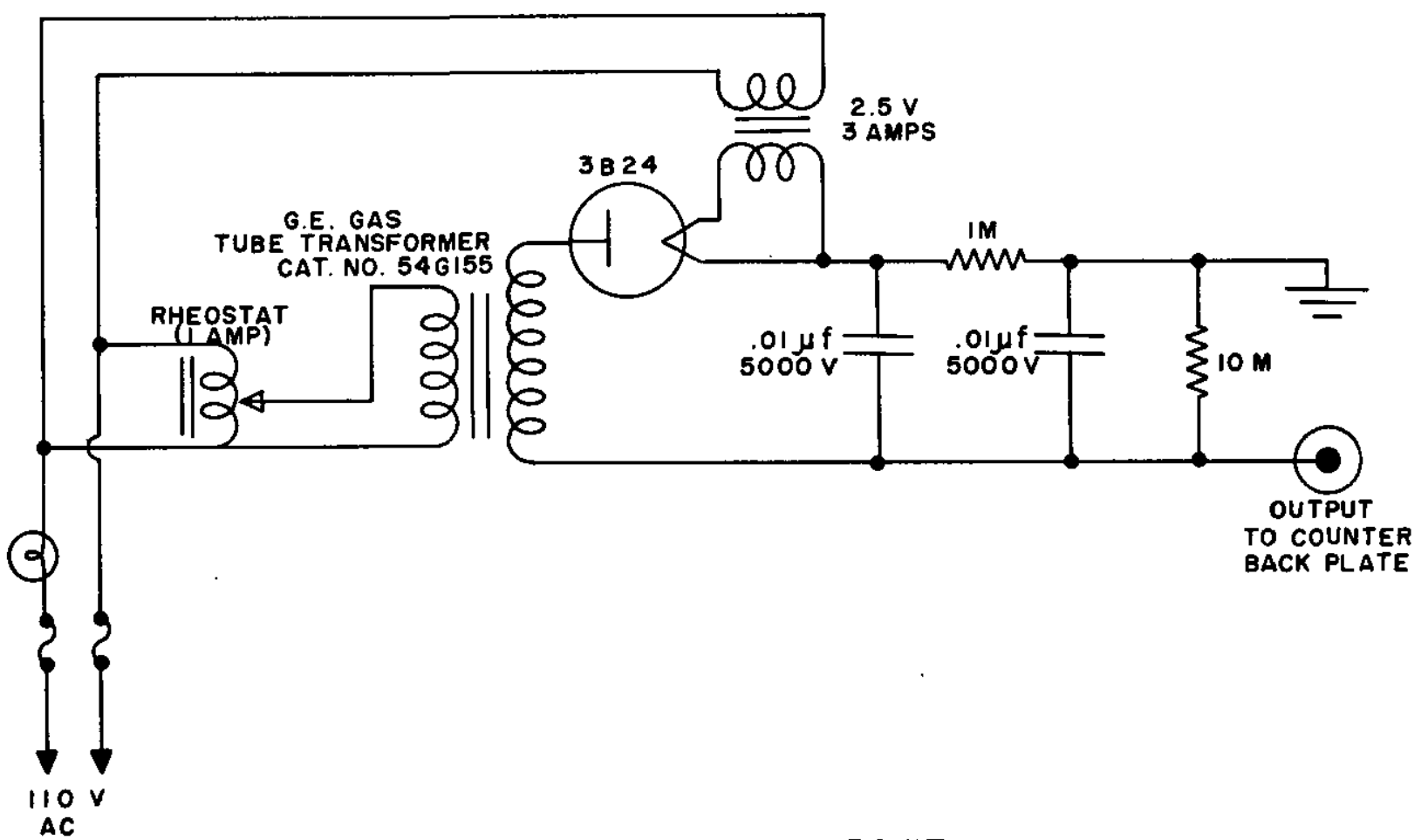

(b),HIGH-VOLTAGE CIRCUIT 


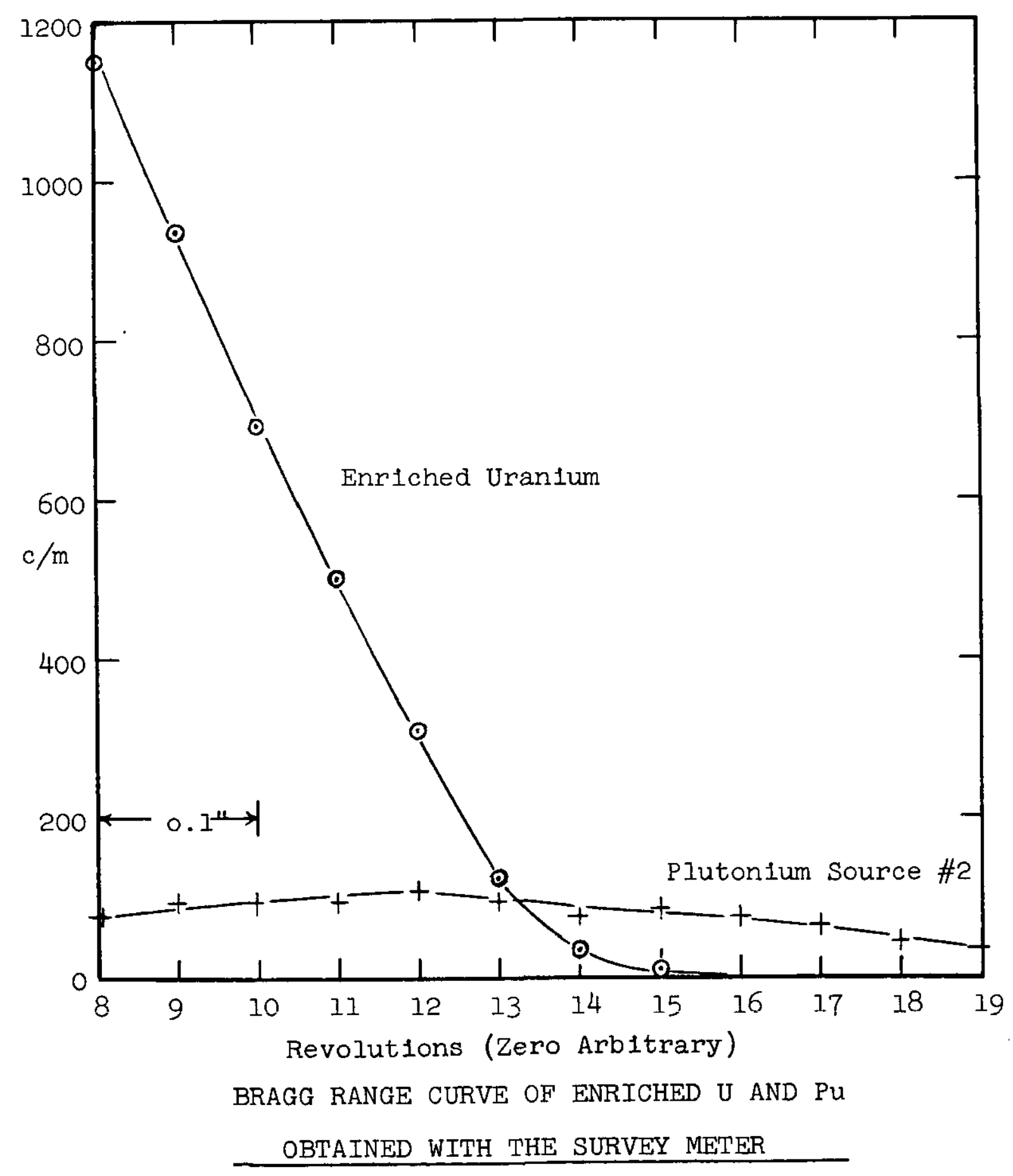


FIGURE 12

DP - 62

Page 23

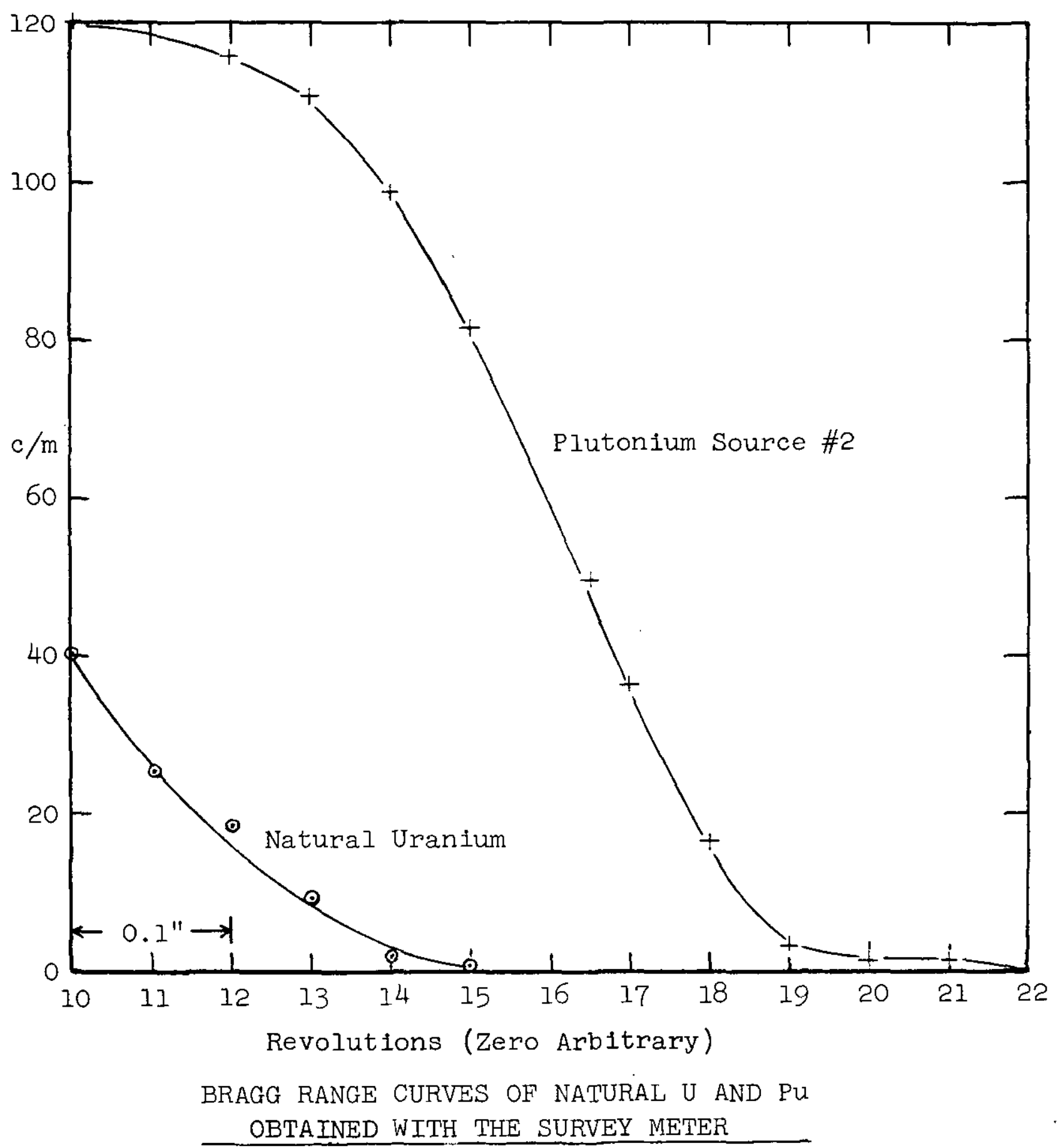

